\title{
Knowledge Attitude and Preparedness among Different Health Professionals Towards Potential Bioterrorism Attacks
}

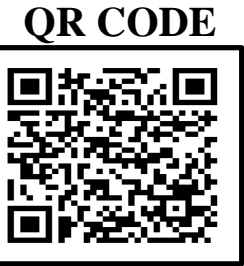

P. ADITHYA TEJA PRASAD*1, VINEELA P², SIVA KUMAR P², YASHWANT SAI ${ }^{3}$, KARISHMA J'1, PRATYUSHA CH. ${ }^{1}$

INTRODUCTION: The threat of bioterrorism, long ignored and denied, has heightened over the past few years. Bioterrorism is the malpractice of microbial agents and their products in-order to create terror or slay humans or animals.

AIM: To assess the knowledge, attitude and preparedness regarding bioterrorism among dental, medical and nursing group of colleges in and around Visakhapatnam, India.

MATERIALS AND METHOD: A descriptive cross-sectional study with structured self-administered questionnaire with 14 validated questions was done among 1,412 health care providers which includes medical and dental interns, postgraduates, nursing third and final year students and faculty that includes both the practitioners and academicians from 6 medical, 2 dental and 3 nursing colleges in and around Visakhapatnam, India. The data was analysed using, Analysis of Variance (ANOVA) test and Tukey's post hoc test. RESULTS: On overall comparison among the three group of colleges, the knowledge, attitude and preparedness concerning bioterrorism is higher in medical colleges, followed by dental colleges and nursing colleges respectively that are statistically significant.

CONCLUSION: Most of the study population are willing to help the government during the outbreak of bioterrorism but lack of knowledge is hindering them. Hence the curriculum of medical, dental and nursing colleges must be reformed and training courses are to be planned for better knowledge, preparedness and attitude of doctors as well as nurses.

KEYWORDS: Bioterrorism, Health Care Providers, Pandemic, Knowledge

\section{INTRODUCTION}

Terrorism can be defined as "a strategy to use violence, social threats, or coordinated attacks to generate fear, cause disruption, and ultimately leading to compliance with specified political, religious, or ideological demands" and this term terrorism is derived from a French word "terrrorisme". Bioterrorism is the intentional or threatened use of microbes or their toxins to produce death or disease in humans, animals or plants to accomplish political or social objectives. ${ }^{2}$

Agents of bioterrorism can be coaxed and persuaded to defy modern medications and can be blown out through various sources that are difficult to detect. Rather than atomic or chemical weapons, microbiological instruments pose the utmost risk, and such agents are gaining prominence around the world. ${ }^{3}$

The history of bioterrorism was started by Assyrians in 600 B.C. when they poisoned enemy wells by a fungus that caused convulsions. During the siege of Caffa in 1346, Tartar forces initiated a plague outbreak that was responsible for the plague pandemic known as the
"Black Death" and was said to be the most devastating public health disaster in history. ${ }^{4}$ In $19^{\text {th }}$ century with new founded knowledge of Koch's postulates and development of modern microbiology, isolation and production of specific pathogens became possible. ${ }^{5}$

Cases of individuals utilizing biological agents for malicious purposes include the 2001 anthrax attack and mailing of letters containing poison ricin to the President, senator, and a local judge in United States in April, 2013. ${ }^{6}$ Maintaining effective disease surveillance and communication systems are fundamental components of an adequate public health infrastructure. ${ }^{7}$ Dentistry can contribute valuable assets, both in personnel, in facilities, and in the immediate response to a bioterrorist attack and its aftermath. Dentists, with their extensive academic training and practical skills, can make a much greater contribution in both the early detection of and response to a bioterrorist event. ${ }^{8}$

As India has a huge population there is every chance for 
quick spread of a pandemic during bioterror attack. But the recommended syllabus given by $\mathrm{MCI}, \mathrm{DCI}$ and $\mathrm{NCI}$ lack the presence of bioterrorism. ${ }^{9}$ Physicians and nurses are integral components of the public health bioterrorism surveillance system. ${ }^{10}$ Hence, need was felt to assess the knowledge, attitude and preparedness regarding bioterrorism amongst the medical, dental and nursing colleges in and around Visakhapatnam regarding bioterrorism.

\section{MATERIALS AND METHOD}

This is a cross sectional study done in and around the Visakhapatnam district, Andhra Pradesh, India for over a period of 2 months. The study population consisted of 1,412 participants in which 364 participants were obtained from 2 dental colleges, 697 participants were obtained from 6 medical colleges and 351 participants were obtained from 3 nursing colleges in and around Visakhapatnam district. The study sample was chosen using convenience sampling. The purpose of the study was explained to every participant, and written informed consent was obtained.

A structured, self-administered questionnaire consisting of 14 closed-ended questions with 6 questions based on knowledge and attitude each and 2 questions based on preparedness regarding bioterrorism was taken from a previous study. ${ }^{1}$ The questionnaire is pretested in a pilot study done on 200 individuals of medical, dental and nursing colleges.

The inclusion criteria consist of: 1) People who are willing to participate in the study from three groups of colleges. 2) Only interns, post graduates and faculty members from dental colleges and medical colleges are included in the study. 3) Third years, final years and faculty members are included from nursing colleges. 4) Participants who gave informed consent.

The questionnaires that are not completely filled and has multiple responses for a question are not included in results.

The collected data were tabulated in Microsoft Excel and subjected to statistical analysis using the Statistical Package for the Social Sciences version 21 software (SPSS Inc., Chicago, IL, United States). The data were analysed using, Analysis of Variance (ANOVA) test and Tukey's post hoc test where $\mathrm{P}$ value $<0.05$ was considered statistically significant.

\section{RESULTS AND DISCUSSION}

Bioterrorism is seen as one of the greatest threats to society as it is a covert, unannounced event that involves the release of an organism or toxin without any public notification. Days or weeks may pass before the release is noticed. A cluster of diseases appearing after the incubation period would potentially signal the event. Health care first responders are likely to be the first to encounter these first cases of disease. Thus, they must possess the knowledge and skills to either rule out suspect agents or refer the case to their public or national health laboratory (depending upon the country) for confirmation. ${ }^{3}$ This study is first of its kind in the literature where study population is taken from medical, dental and nursing colleges to assess their knowledge, attitude and preparedness regarding bioterrorism.

In this present study participants of medical, dental and nursing colleges had mean values of $1.52,1.35$ and 1.25 respectively regarding knowledge about the term bioterrorism and about the fact that terrorists can use biological agents for spreading terror which are in line with the results in studies done by Chaudhari A et al. (2011), ${ }^{1}$ Kshirsagar, MM et al. (2017) ${ }^{11}$ and Bhatt $S$ et al. $(2014)^{12}$ regarding dental colleges. The results were in contrast with study done by Moghadam BSA et al. $(2016)^{13}$ where a very low percentage of study participants had knowledge regarding bioterrorism. The difference might be due to the fact that their study has been done on participants who are not health professionals.

The mean values for the knowledge on the categories given by CDC in the three groups of colleges are 2.11, 2.37 and 2.03 in dental, medical and nursing group of colleges respectively. Among the three groups of colleges, more percentage of the study participants among the dental colleges believe that dentists had a role during the event of bioterrorism. The overall knowledge regarding bioterrorism is higher among the medical college participants.

The study participants among the medical colleges has shown statistically significant mean values for observation of oral or cutaneous lesions other than the chief complaint during routine examination and monitoring of unusual signs and symptoms that might be an early sign of bioterror attacks. The study participants of medical colleges are having higher mean 


\begin{tabular}{|c|c|c|c|c|c|c|c|}
\hline \multicolumn{8}{|c|}{ Health Care } \\
\hline & \multirow[t]{2}{*}{ Providers } & \multicolumn{2}{|c|}{ Medical } & \multicolumn{2}{|c|}{ Dental } & \multicolumn{2}{|c|}{ Nursing } \\
\hline & & $\mathbf{n}$ & $\%$ & $\mathbf{n}$ & $\%$ & $\mathbf{n}$ & $\%$ \\
\hline \multirow[t]{2}{*}{ No. of respondents } & Approached & 750 & \multirow[t]{2}{*}{$92.93 \%$} & 375 & \multirow[t]{2}{*}{$97.07 \%$} & 375 & \multirow[t]{2}{*}{$93.6 \%$} \\
\hline & Responded & 697 & & 364 & & 351 & \\
\hline \multirow[t]{2}{*}{ Gender } & Male & 279 & $40 \%$ & 156 & $42.9 \%$ & 139 & $39.6 \%$ \\
\hline & Female & 418 & $60 \%$ & 208 & $57.1 \%$ & 212 & $60.4 \%$ \\
\hline \multirow{3}{*}{ Qualification } & Postgraduates & 83 & $11.9 \%$ & 51 & $14.01 \%$ & - & - \\
\hline & Undergraduates & 435 & $62.4 \%$ & 166 & $45.6 \%$ & 275 & $78.34 \%$ \\
\hline & Faculty & 179 & $25.6 \%$ & 147 & $40.27 \%$ & 76 & $21.6 \%$ \\
\hline
\end{tabular}

Table 1. Demographic Data of Study Population

values regarding practice followed by dental and nursing colleges.

In study done by Bhatt $\mathrm{S}$ et al. (2014), ${ }^{12}$ postgraduate students showed a higher self-perceived knowledge compared to the undergraduates and in study done by Kshirsagar MM et al. (2017) ${ }^{11}$ the results show that $75.2 \%$ of the dentists were confident in recognition of signs and symptoms of bioterrorism-related diseases and $78.3 \%$ were aware about the commonly used agents related to it. Results in study done by Chaudhari A et al. (2001) ${ }^{1}$ showed that almost $88 \%$ of both medical and dental interns do check for intraoral or cutaneous lesion other than the chief complaint and $77 \%$ of medical interns can monitor any unusual and unexplained signs and symptoms that may be an early warning or sign of community-wide infections or a bioterror attack while only $50 \%$ of dental interns were able to monitor such signs and symptoms.

Most of the study participants are in favour of curriculum development and are willing to undergo additional training programs regarding bioterrorism. The mean values regarding willingness towards additional training programs regarding bioterrorism are almost similar among dental, medical and nursing colleges. Almost $73 \%$ of both medical and dental college study population along with almost $57 \%$ of nursing college study population are willing for curriculum development and additional training programs regarding bioterrorism. Studies done by Chaudhari A et al. (2011) ${ }^{1}$, Bhatt $\mathrm{S}$ et al. $(2014)^{12}$, Moghadam BSA et al. $(2016)^{13}$, Brown C et al. (2010) $)^{14}$, Aghaei N et al. (2013) ${ }^{15}$,
Sridevi V et al. (2020) ${ }^{16}$ are in favour of need for training regarding bioterrorism.

Among the study participants most of the medical and dental college participants followed by the nursing college participants are willing to provide help to the government during the event of bioterrorism. The studies done by Chaudhari A et al. (2011) ${ }^{1}$, Katz AR et al. (2006) ${ }^{17}$, Bhatt $S$ et al. (2014) $)^{12}$, also show willingness and positive response to help the government in bioterror outbreak.

The results of nursing colleges regarding the knowledge about the term bioterrorism are in line with studies done by Brown C et al. (2014) $)^{14}$, Aghaei N et al. (2013) Rebmann T et al. (2010) ${ }^{18}$ and Mosca NW et al. (2005) ${ }^{19}$ in which results demonstrated that nurses have considerable lack of confidence in their knowledge and skill ability concerning bioterrorism and disaster preparedness. As no postgraduates from the nursing colleges are included in the study, this could have affected the results of nursing colleges regarding knowledge, attitude and preparedness regarding bioterrorism.

The differences among the three group of colleges on knowledge, attitude and practice regarding bioterrorism might be due to the differences in their curricula and different rates of exposure towards the patients. As health professionals play a key role during the event of bioterrorism which is a global health threat, they must possess good versatile knowledge and practice regarding the management of bioterror events. 


\begin{tabular}{|c|c|c|c|c|}
\hline $\begin{array}{c}\text { Questions on knowledge of } \\
\text { bioterrorism }\end{array}$ & $\begin{array}{l}\text { Dental Health } \\
\text { care providers }\end{array}$ & $\begin{array}{l}\text { Medical Health } \\
\text { care providers }\end{array}$ & $\begin{array}{l}\text { Nursing Health } \\
\text { care providers }\end{array}$ & p value \\
\hline \multicolumn{5}{|c|}{ QUESTIONS ON KNOWLEDGE REGARDING BIOTERRORISM } \\
\hline 1. Knowledge on bioterrorism & $1.35 \pm 0.54$ & $1.52 \pm 0.53$ & $1.25 \pm 0.62$ & 0.01 \\
\hline 2. Awareness on bioterrorism & $1.27 \pm 0.59$ & $1.31 \pm 0.58$ & $1.21 \pm 0.67$ & 0.01 \\
\hline 3. Anthrax attack in USA (2001) & $1.40 \pm 0.58$ & $1.51 \pm 0.60$ & $1.36 \pm 0.63$ & $0.001^{*}$ \\
\hline 4. Categories given by CDC & $2.11 \pm 0.91$ & $2.37 \pm 0.94$ & $2.03 \pm 0.81$ & 0.01 \\
\hline 5. Agents & $4.05 \pm 2.14$ & $4.18 \pm 2.2$ & $3.43 \pm 2.27$ & 0.01 \\
\hline 6. Role of Dentists & $1.57 \pm 0.73$ & $1.54 \pm 0.78$ & $1.41 \pm 0.84$ & 0.01 \\
\hline \multicolumn{5}{|c|}{ QUESTIONS ON PREPAREDNESS REGARDING BIOTERRORISM } \\
\hline $\begin{array}{l}\text { 7. Observation during routine } \\
\text { examination }\end{array}$ & $1.57 \pm 0.76$ & $1.75 \pm 0.79$ & $1.49 \pm 0.81$ & $0.000^{*}$ \\
\hline $\begin{array}{l}\text { 8. Monitoring unusual signs and } \\
\text { symptoms }\end{array}$ & $1.68 \pm 0.78$ & $1.86 \pm 0.80$ & $1.55 \pm 0.78$ & 0.01 \\
\hline \multicolumn{5}{|c|}{ QUESTIONS ON ATTITUDE REGARDING BIOTERRORISM } \\
\hline 9. Confidence level & $1.49 \pm 0.72$ & $1.78 \pm 0.69$ & $1.40 \pm 1.51$ & 0.01 \\
\hline 10. Curriculum development & $1.53 \pm 0.64$ & $1.67 \pm 0.63$ & $1.38 \pm 1.44$ & $0.001^{*}$ \\
\hline $\begin{array}{l}\text { 11. Preparedness and planning } \\
\text { for counter-terrorism }\end{array}$ & $1.75 \pm 0.66$ & $1.91 \pm 0.62$ & $1.51 \pm 1.67$ & $0.001^{*}$ \\
\hline 12. Additional training program & $1.48+0.62$ & $1.55 \pm 0.59$ & $1.39 \pm 1.39$ & $0.001^{*}$ \\
\hline 13. Help the government & $1.44 \pm 0.72$ & $1.56 \pm 0.66$ & $1.31 \pm 0.82$ & 0.01 \\
\hline 14. Self-assessment & $2.77 \pm 0.89$ & $2.91 \pm 0.83$ & $2.62 \pm 0.82$ & 0.01 \\
\hline
\end{tabular}

Table 2. Mean Values of Knowledge, Preparedness and Attitude among the Three Groups of Colleges Regarding Questionnaire on Bioterrorism. ANOVA with Tukey's Post Hoc test. * Denotes Highly Significant p Value

In order to achieve this, the curricula should to be reformed according to the present situations with the incorporation of bioterrorism. There is a greater need for additional training programs regarding counter terrorism and management for the improvement of knowledge and skills of the health professionals. Continuation of educational programs, webinars are to be taken place on a regular basis through which both the students as well as professionals can gain knowledge regarding bioterrorism.

As there is a limited data in the literature regarding bioterrorism there is need for more studies to be done in future. The limitations of this study are, no post graduates from the nursing colleges are included in the study and the study is limited to area in and around Visakhapatnam district, India.

\section{CONCLUSION}

Most of the study participants are willing to help the government during the outbreak of bioterrorism but lack of knowledge is hindering them. Hence the curriculum of medical, dental and nursing colleges must be reformed and training courses are to be planned for better knowledge, practice and attitude of doctors as well as nurses. Successfully meeting the challenges of bioterrorism requires a multifaceted response. No single approach will by itself be successful. 
The key countermeasures for bioterrorism include the act of deterrence, prevention by reducing the opportunity and enhancing intelligence, surveillance and assessment by epidemiological methods and finally medical management through preventive, promotive, curative services, training and education of health care providers.

\section{REFERENCES}

1. Chaudhari A, Shetiya SH, Kakodkar P, Shirahatti R. Knowledge, attitude and practice regarding bioterrorism amongst the medical and dental interns in Dr. D.Y. Patil deemed university - A questionnaire study. J Indian Assoc Public Health Dent. 2011;9: 94-9. 2. Fong I, Alibek K (2010). Bioterrorism and infectious agents. New York, NY: Springer Science \& Media, Inc. 3. Dworkin MS, Ma X, Golash RG. Fear of bioterrorism and implications for public health preparedness. Emerg Infect Dis. 2003;9:503-5.

4. Wheelis M. Biological warfare at the 1346 siege of Caffa. Emerg Infect Dis 2002;8:971-5.

5. Robertson AG, Robertson LJ. From asps to allegations: biological warfare in history. Mil Med 1995; 160: 369-73.

6. Riedel S. Biological warfare and bioterrorism: a historical review. Proc Bayl Univ Med Cent. 2004;17: 400-6.

7. Das S, Kataria VK. Bioterrorism: A Public Health Perspective; MJAFI. 2010;66(3):255-69.

8. Guay AH. Dentistry's response to bioterrorism A report of a consensus workshop. JADA 2002;133:1181-7.

9. Syal S. Bioterrorism: time to wake up. Current Science 2008;95(12):1665-6.

10. Kate AR, Nekorchuk DM, Hoick PS, Hendrickson LA, Imrie AA, Effler PV. Hawaii Physician and Nurse Bioterrorism Preparedness Survey. Prehospital and Disaster Medicine 2006;21(6):404-11.

11. Kshirsagar MM, Dodamani AS, Vishwakarma PY, Dodamani GA, Jadhav HC, Bhandari RC. Assessment of
Knowledge and Attitude of Dentists Toward Bioterrorism Awareness in Dhule (Maharashtra, India): A Cross-sectional Survey. J Indian Assoc Public Health Dent. 2017; 15:57-60

12. Bhatt S, Rajesh G, Thakur D. Knowledge, Perceived Need for Education, and Willingness to Participate in Bioterrorism Preparedness among Students in an Indian Dental Institute: A Questionnaire Study; Med J DY Patil Vidyapeeth 2017;10:526-31.

13. Moghadam BSA, Pour SH, Toorchi M, SefidiHeris Y. Knowledge and Attitude of Iranian Red Crescent Society Volunteers in Dealing with Bioterrorist attacks. Emergency. 2016;4(1):16-20.

14. Brown C, editor. Are Nurses Prepared for a Radiological Disaster?: Assessing the Knowledge of Nursing Students to Support the Need of Integrating Radiological/Disaster Content Into Nursing Curricula. Sigma Theta Tau International's $25^{\text {th }}$ International Nursing Research Congress; 2014; Hong Kong: Sigma Theta Tau International.

15. Aghaei N, Nesami MB. Bioterrorism education effect on knowledge and attitudes of nurses. J Emerg Trauma Shock. 2013;6(2):78-82.

16. Sridevi V, Vikram Simha B, Gayathri Naidu SS, Chowdary KH, Yaragani A, Sree YS. Awareness on Bioterrorism among qualified dentists in a teaching dental institution in southern India. J NTR Univ Health Sci. 2020;9:32-6.

17. Katz AR, Nekorchuk DM, Holck PS, Hendrickson LA, Imrie AA, Effler PV. Dentists' preparedness for responding to bioterrorism: A survey of Hawaii dentists. JADA 2006;137:461-7.

18. Rebmann T, Mohr LB. Bioterrorism knowledge and educational participation of nurses in Missouri. J Contin Educ Nurs. 2010;41(2):67-76.

19. Mosca NW, Sweeney PM, Hazy JM, Brenner P. Assessing Bioterrorism and Disaster Preparedness Training Needs for School Nurses; J Public Health Management Practice. 2005:S38-S44. 
Source of support: Nil, Conflict of interest: None declared

Cite this article as:

Adithya P, Vineela P, Kumar SP, Sai Y, Karishma J, Pratyusha CH. Knowledge

Attitude and Preparedness among Different Health Professionals Towards

Potential Bioterrorism Attacks. Int Healthc Res J. 2020;4(4):92-97.

https://doi.org/10.26440/IHRJ/0404.07160

\section{AUTHOR AFFILIATIONS: $\left({ }^{*}\right.$ Corresponding Author)}

1. Post Graduate Student

2. Reader

3. Senior Lecturer

Department of Public Health Dentistry, Anil Neerukonda Institute of Dental Sciences, Sangivalasa, Bheemunipatnam Mandal,

Visakhapatnam (Dt), Andhra Pradesh-531163

Contact corresponding author at: adithyatejaor[at]gmail[dot]com 